\title{
SERUM MAGNESIUM LEVELS IN AORTIC AND MITRAL VALVE REPLACEMENT SURGERIES
}

Srinivasa Rao Gondi1 ${ }^{1}$, Venkata Sesha Sai Krishna Manne ${ }^{2}$

\section{HOW TO CITE THIS ARTICLE:}

Srinivasa Rao Gondi, Venkata Sesha Sai Krishna Manne. "Serum Magnesium Levels in Aortic and Mitral Valve Replacement Surgeries". Journal of Evolution of Medical and Dental Sciences 2015; Vol. 4, Issue 64, August 10; Page: 11123-11128, DOI: $10.14260 /$ jemds/2015/1603

ABSTRACT: BACKGROUND: The purpose of the study was to analyze serum magnesium concentration in patients undergoing Aortic and Mitral Valve replacement surgeries. METHODS: This prospective study was conducted in 60 patients who underwent elective Aortic and Mitral valve replacement surgeries. Blood samples from radial artery were collected just before induction of anesthesia and three days post-operatively for estimation of serum magnesium. RESULTS: Magnesium level was $2.02 \mathrm{mg} / \mathrm{dl}$ at baseline, $2.28 \mathrm{mg} / \mathrm{dl}, 2.08 \mathrm{mg} / \mathrm{dl}$ and $1.90 \mathrm{mg} / \mathrm{dl}$ respectively on three consecutive days post-operatively. CONCLUSION: The lowering of serum magnesium in Aortic and Mitral valve replacement surgeries postoperatively recommends the use of routine serum magnesium determination and administration to prevent post-operative arrhythmias.

KEYWORDS: Aortic Valve Replacement, Magnesium, Mitral Valve Replacement.

INTRODUCTION: Serum Magnesium plays an important role in cardiac protection.

Magnesium has many beneficial effects like it improves contractility and reduces the number of cardiac arrhythmia episodes.

Magnesium is not a trace element but the most abundant essential mineral in the body and fourth most abundant intracellular cation.

Free magnesium $\left(\mathrm{Mg}^{2+}\right)$ is involved in numerous processes of cardiac function. However mechanism of regulation by magnesium has not been fully understood.

Physiological roles of magnesium include its action as a regulator of $\mathrm{Ca}^{2+}, \mathrm{K}^{+}$and $\mathrm{Na}^{+}$transport channels and pumps in cell membranes. ${ }^{1}$

Magnesium is distributed approximately one half in the bone, one half in the muscle and other soft tissues, less than one percent is in the blood.

Magnesium is an important regulator of multiple cardiovascular processes, including myocardial contraction and conductivity, transmembrane calcium flux, potassium transport, vascular smooth muscle tone, coronary reactivity and nitric acid synthesis.

Magnesium is an essential cofactor for the maintenance of myocardial transmembrane potential, magnesium deficiency decreases the threshold of arrhythmia. ${ }^{1}$

Magnesium depletion is known to cause supra-ventricular arrhythmias, atrial fibrillation, lengthened P-R and Q-T segments or ventricular fibrillation. ${ }^{2}$

Atrial fibrillation is the most common cardiac arrhythmia after cardiac surgery. There is a strong association between atrial fibrillation and thrombo embolic complications.

The main cause of thromboembolic complications is multifactorial but may be attributed to a hypercoaguable state with hemostatic abnormalities and endothetical dysfunction in $\mathrm{AF}^{3}$

Several analyses showed the effectiveness of magnesium on post-cardiac surgeries atrial fibrillation. $4,5,6$ 


\section{ORIGINAL ARTICLE}

Magnesium has also been considered as a safe adjunct to digoxin in controlling the ventricular response in acute atrial fibrillation. 6

\section{Magnesium may Influence the Incidence of Cardiac Arrhythmias by:}

a) A direct effect.

b) An effect on potassium metabolism.

c) An effect as a calcium blocking agent.

In the event of a magnesium deficiency the cell cannot attract potassium against the transmembrane concentration gradient. The reason may be that a magnesium deficiency interferes with the function of membrane ATP and thus the pumping of sodium out from the cell and potassium into the cell is impaired.

The interference from a magnesium deficiency on the equilibrium of potassium between the intra and extra cellular spaces may result in changes in the resting membrane potential, changes in potassium conductance across the cell membrane as well as disturbances in the repolarization phase. Magnesium is also an essential constituent of many enzyme systems in the body and plays a physiological role in the regulation of coagulation system of the body. It has also been proved that in situation of rapid IV fluid infusion, maintaining the magnesium at the upper limit of normal value attenuates rapid hemodilution-induced coagulation change due to decreased magnesium level in healthy volunteers. ${ }^{7}$

There were also some studies that magnesium interrupted platelet aggregation and adhesion so magnesium sulphate administration induced hypo coagulation state.8,9

The aim of the present study was to determine the serum may level three days postoperatively in Mitral valve repair and replacement surgeries.

MATERIALS AND METHODS: The prospective study was conducted at NRI medical college and hospital on 60 consecutive patients who underwent Mitral valve and Aortic valve replacement surgeries. The study was approved by institutional ethics committee and informed consent was obtained from all patients.

35 males and 25 females with the age group 18-50 years were included in the study.

\section{PRE-OP DEMOGRAPHIN:}

Inclusion Criteria: Mitral valve and Aortic valve replacement surgeries with $\mathrm{EF}>45 \%$.

Exclusion Criteria: Emergency surgeries and patients receiving oral or injectable magnesium, severe hepatic or renal disease (S. creatinine $>2.0 \mathrm{mg} / \mathrm{dl}$ ), patients on oral furosemide tablets.

SURGICAL PROCEDURE: Standard surgical procedure was applied for all cases. After midline incision; sternotomy was done followed by pericardial opening. After achieving adequate anticoagulation aorta was cannulated, then followed by superior vena cava and inferior vena cava cannulation. After cross clamping of aorta heart was arrested with infusion of cold blood cardioplegia. After the heart was arrested appropriate surgery was carried out. After surgery the patient was rewarmed gradually to normal body temperature and weaned off the bypass with inotropic support of dobutamine and noradrenaline. 


\section{ORIGINAL ARTICLE}

After protamine reversal and adeqauate hemostasis sternum was closed with steel wires. Chest was closed in layers and patient was shifted to post-operative ICU for elective ventilation.

\section{The Blood Sample was collected from Radial Artery:}

1. Just before anesthesia after cannulation.

2. $1^{\text {st }}$ post-operative day.

3. $2^{\text {nd }}$ post-operative day.

4. $3^{\text {rd }}$ post-operative day.

The blood was immediately centrifuged at $3000 \mathrm{rpm}$ at room temperature after clotting and the obtained serum was determined by colorimetric method using xylidyl blue.

ANESTHETIC REGIMEN: On the day of surgery the patients were premedicated with fentanyl $(1 \mu \mathrm{g} / \mathrm{kg})$ and midazolam $2 \mathrm{mg}$ then they were induced with thiopentone $\left(5 \mathrm{mg} \mathrm{kg}^{-1}\right)$ and vecuronium was used to accomplish endotracheal intubation with appropriately sized tube (Generally $9.0 \mathrm{~mm}$ foe males and $7.5 \mathrm{~mm}$ foe females). Anesthesia was maintained with $50 \%$ Nitrous Oxide $\left(\mathrm{N}_{2} \mathrm{O}\right)$ along with sevoflurane (1.5\% MAC) the vitals are maintained with the use of dobutamine, noradrenaline and nitroglycerine. Fentanyl $\left(1 \mu \mathrm{gkg}^{-1}\right)$ was given before incision foe analgesia.

Anticoagulation is achieved with heparin $3 \mathrm{mg} / \mathrm{kg}$ to maintain activated clotting time of more than 480 seconds. Adequate mean arterial pressure and urine output is maintained during cardiopulmonary bypass and throughout surgery.

After surgery anticoagulation is reversed with protamine with 1:1 ratio with heparin. The target ACT was baseline ACT, hemoglobin was maintained at $10 \mathrm{mg} / \mathrm{dl}$. A normal arterial blood gas analysis was maintained. Adequate hemostasis was achieved before chest closure. After that patient was shifted to post-operative intensive care unit foe elective ventilation. Most of the patients are extubated within 6-8 hours of surgery. Ionotropes are gradually weaned off.

MAGNESIUM ADMINISTRAION: $40 \mathrm{mg} / \mathrm{dl}$ of magnesium sulphate (50\%) in $100 \mathrm{ml}$ normal saline was given intravenously over 15 minutes after induction of anesthesia.

RESULTS: The patients in the study were in the age group of 18 - 50 years with 35males 25 females.

\begin{tabular}{|c|c|c|c|}
\hline Age (years) & Male & Female & Total \% \\
\hline $10-19$ & 2 & 1 & $5 \%$ \\
\hline $20-29$ & 18 & 14 & $53.34 \%$ \\
\hline $30-39$ & 9 & 6 & $25 \%$ \\
\hline $40-49$ & 6 & 4 & $16.66 \%$ \\
\hline Total (n) & $\mathbf{3 5}$ (n) & $\mathbf{2 5}$ (n) & $\mathbf{1 0 0 \%}$ \\
\hline
\end{tabular}

Mean age $=30.16$.

$\mathrm{SD}=8.789$. 


\section{ORIGINAL ARTICLE}

\begin{tabular}{|c|c|c|c|c|c|}
\hline Sl. No. & Serum Magnesium levels & Baseline & $1^{\text {st }}$ POD & $2^{\text {nd }}$ POD & $3^{\text {rd }}$ POD \\
\hline 1) & $1.51-1.70$ & - & - & - & 6 \\
\hline 2) & $1.71-1.90$ & 2 & 1 & 1 & 40 \\
\hline 3) & $1.91-2.10$ & 30 & 15 & 42 & 14 \\
\hline 4) & $2.11-2.30$ & 23 & 35 & 16 & - \\
\hline 5) & $2.31-2.50$ & 5 & - & 1 & - \\
\hline & Total (n) & 60 & 60 & 60 & 60 \\
\hline
\end{tabular}

The observed difference of serum magnesium levels between baseline value and 3rd POD is statistically highly significant with $\mathrm{P}<0.01$.

DISCUSSION: Magnesium as the second most abundant intracellularcation in the body has an important function of stabilizing the cell membrane.

The effect of magnesium on myocardial tissues leads to many cardiac arrhythmias in valve replacement surgeries. Magnesium deficiency can lead to cardiac arrhythmias, coronary artery spasm modification of cardiac conduction and neurological irritability ${ }^{1,2}$ magnesium also reduces palatelet aggregation depress catecholamine release and decrease coronary and systemic vascular resistance.3,4

Prophylactic administration of magnesium in heart surgeries may improve cardiac contractile indices after cardiopulmonary bypass. ${ }^{5,6}$ So intravenous magnesium infusion is a good method to connect hypomagnesemia. ${ }^{10}$

Kiziltep et.al has proved that magnesium is a safe anti arrhythmic agent in open heart surgeries. So it can be used as a first line anti arrhythmic agent even without measurement of blood levels.

Magnesium has an essential role in numerous cellular procedures and if its metabolism is disturbed it can have serious biological consequences.

Hypo magnesia is a common disorder after cardiac surgeries and has a higher frequency in patients with AF.4,10

Therefore, a magnesium infusion is highly effective prophylactic therapy for reducing the incidence of AF after cardiac surgery. ${ }^{4,11}$

It has also been studied that magnesium infusion significant increases atrial refractoriness. ${ }^{12,13}$

Same studies have reported that low left atrial wall tension and near normal size of left atrium were important factors to maintain normal sinus rhythm after Mitral valve surgeries. ${ }^{14}$

Mitral valular disease, increased left atrial pressure and volume overload, which lead to left atrial enlargement in frequently associated with AF. The incidence of AF is known as 30-40\% in patients presenting with Mitral valve surgery. ${ }^{15}$

Pre-operative magnesium infusion was more effective in prevention of post-operative AF, comparing with intra or post-operative magnesium infusion is a meta-analysis by Miller et $\mathrm{al}^{4}$ and post-operative AF usually has a self-limited course.16,17 


\section{ORIGINAL ARTICLE}

CONCLUSION: The lowering of magnesium after post Coronary Artery Bypass Grafting on cardio pulmonary bypass, three days post operatively recommends the routine serum magnesium administration to prevent complications like atrial and ventricular arrhythmias.

ACKNOWLEDGMENT: The authors wish to thank the operating room personnel, the intensive care nursing staff and the department of Biochemistry, NRI Medical College \& Hospital for their support in this clinical investigation.

\section{REFERENCES:}

1. Rude RK. Physiology of magnesium metabolism and the important role of magnesium in potassium deficiency. Am J Cardiol 1989; 63: 31-4G.

2. Wacker WEC. Magnesium and Man.Chpt 1. Harvard University Press, Cambridge, MA, London, 1980.

3. Lip GY. Does atrial fibrillation confer a hypercoagulable state? Lancet 1995; 346: 1313-4.

4. Miller S, Crystal E, Garfinkle M, Lau C, Lashevsky I, Connolly SJ.Effects of magnesium on atrial fibrillation after cardiac surgery: ameta-analysis. Heart 2005; 91: 618-23.

5. Onalan 0, Crystal E, Daoulah A, Lau C, Crystal A, Lashevsky I.Meta-analysis of magnesium therapy for the acute management ofrapid atrial fibrillation. Am J Cardiol 2007; 99: 1726-32.

6. Ho KM, Sheridan DJ, Paterson T. Use of intravenous magnesium to treat acute onset atrial fibrillation: a meta-analysis. Heart 2007; 93:1433-40.

7. Ruttmann TG, Montoya-Pelaez LF, James MF. The coagulation changes induced by rapid in vivo crystalloid infusion are attenuated when magnesium is kept at the upper limit of normal. Anesth Analg 2007; 104: 1475-80.

8. Gries A, Bode C, Gross S, Peter K, Bohrer H, Martin E. The effect of intravenously administered magnesium on platelet function inpatients after cardiac surgery. Anesth Analg 1999; 88: 1213-9.

9. Gawaz M, Ott I, Reininger AJ, Neumann FJ. Effects of magnesium on platelet aggregation and adhesion. Magnesium modulates surface expression of glycoproteins on platelets in vitro and ex vivo. Thromb Haemost 1994; 72: 912-8.

10. Chadda KD, Lichstein E, Gupta P (1973) Hypomagnesaemia and refractory cardiac arrhythmia in a non-digitalized patient. Am I Cardiol 31 (1): 98-100.

11. Satur CM, Jennings A, Walker DR (1993) Hypomagnesaemia and fits complicating pediatric cardiac surgery. Ann Clin Biochem 30(pt 3): 315-317.

12. James MF, Beer RE, Esser JD (1989) Intravenous magnesium sulfate inhibits catecholamine release associated with tracheal intubation Anesth Analg 68(6): 772-776.

13. Sjogren A, Edvinsson L, L, Ottosson A (1986) vasomotor responses of isolated human coronary arteries to magnesium, nitroglycerin and verapamil: a comparison with coronary arteries from cat and rat. Acta Pharmacol Toxicol 59 (3): 195-203.

14. Khan RM, Hodge JS, Bassett HF (1973) Magnesium in open-heart surgery. J Thorac Cardiovasc Surg 66(2): 185-191.

15. Scheinman MM, Sullivan RW, Hyatt KH (1969) Magnesium metabolism in patients undergoing cardiopulmonary bypass. Circulation 39(5 suppl): I 235-I 241. 


\section{ORIGINAL ARTICLE}

16. Kaplan M, sinan M, Icer UA, Demirtas MM (2003) Intravenous magnesium sulfate prophylaxix for atrial fibrillation after coronary artery bypass surgery. J thorac Cardiovasc Surg 125(2): 344-352.

17. Wronska J, Dabrowski W, Biernacka J (2005) the effect of normo volemichae modilution on blood magnesium concentrations in patients undergoing extracorporeal circulation. Ann Univ Mariae Curie-Sklodowskasectio D 60: 610-616.

\section{AUTHORS:}

1. Srinivasa Rao Gondi

2. Venkata Sesha Sai Krishna Manne

\section{PARTICULARS OF CONTRIBUTORS:}

1. Professor, Department of Anaesthesia, NRI Medical College \& General Hospital.

2. Associate Professor, Department of Anaesthesia, NRI Medical College \& General Hospital.

\section{NAME ADDRESS EMAIL ID OF THE} CORRESPONDING AUTHOR:

Srinivasa Rao Gondi, Professor.

Department of Anaesthesia, NRI Medical College \& General Hospital, Chinakakani, Guntur-522503.

E-mail: drsrinivas_g@yahoo.co.in

Date of Submission: 17/07/2015. Date of Peer Review: 18/07/2015. Date of Acceptance: 03/08/2015. Date of Publishing: 07/08/2015. 